\title{
ESTUDO DE SISTEMA DE CONTROLE DE VAZÃO DE ÁGUA DE ENXÁGUE COM SET-POINT VARIÁVEL SOBRE A CINÉTICA DE REMOÇÃO DE RESÍDUOS DE SOLUÇÃO DETERGENTE ALCALINA EM TROCADOR DE CALOR FEIXE TUBULAR
}

\author{
V. G. SOUSA ${ }^{1}$, L. dos R. A. CARNEIRO ${ }^{1}$, L. KUNIGK ${ }^{2}$, V. L. CARDOSO ${ }^{1}$ e \\ R.GEDRAITE ${ }^{1}$ \\ ${ }^{1}$ Universidade Federal de Uberlândia, Faculdade de Engenharia Química \\ 2 Centro Universitário do IMT, Departamento de Engenharia Química e de Alimentos
}

\begin{abstract}
RESUMO - Este artigo apresenta uma contribuição acerca da investigação sobre o emprego de vazões variáveis de água de enxágue na cinética de remoção de resíduos de solução detergente alcalina em trocador de calor feixe tubular. O estudo foi baseado na técnica de limpeza tradicionalmente empregada em sistemas de limpeza CIP da indústria. O modelo do processo foi implementado no aplicativo simulink ${ }^{\circledR}$ do matlab®. O emprego de vazões variáveis se mostrou eficaz na remoção dos resíduos, além de economizar água de enxágue contribuindo para minimizar o volume total de água utilizado no processo. Foi constatada uma economia da ordem de $3 \%$ no volume de água gasto.
\end{abstract}

\section{INTRODUÇÃO}

A técnica de limpeza Clean-in-Place (CIP) é amplamente utilizada na indústria de alimentos e na indústria farmacêutica, dentre outras, visando evitar a parada de produção e a desmontagem parcial ou total dos equipamentos de processamento. Sabe-se que diversas pesquisas têm sido realizadas nos últimos anos para procurar formas de melhorar o procedimento (Bansal e Chen, 2006; Bremer et al., 2006). Tanto a tensão de cisalhamento aplicada quanto as reações químicas entre o fluido em escoamento e os depósitos formados são importantes na remoção de incrustações.

A indústria de laticínios sofre de problemas específicos associados com a limpeza de equipamentos de processo, incluindo trocadores de calor (Georgiadis et al., 1998). Presentemente, o procedimento de limpeza envolve a lavagem do maquinário com solução detergente diluída, a fim de remover adequadamente os resíduos e incrustações que tendem a favorecer a contaminação. Depois de terminada a limpeza, o equipamento de processo deve ser enxaguado criteriosamente para remover todos os vestígios dos agentes de limpeza.

Este trabalho apresenta uma contribuição ao tema, estudando a economia de água na etapa de remoção de resíduos de solução de detergente alcalino utilizado em processo CIP aplicado a protótipo de trocador de calor feixe tubular, durante a etapa de enxágue posterior à etapa de limpeza alcalina. Importante ressaltar que Bicalho, Kunigk e Gedraite (2015) 
estudaram esse mesmo processo, avaliando o efeito do emprego de vazões variáveis de água de enxágue sobre a cinética de remoção de resíduos de solução detergente alcalina.

\section{MATERIAIS E MÉTODOS}

Na Figura 1 é apresentada a planta-piloto utilizada neste trabalho, a qual foi operada em regime descontínuo, e formada basicamente pelos seguintes elementos: (i)- tanque principal em aço inox com capacidade de aproximadamente $250 \mathrm{~L}$, (ii)- trocador de calor do tipo casco e tubos em aço inox, (iii)- bomba de deslocamento positivo para movimentação do produto alimentício, (iv)- bomba centrífuga para a movimentação do agente de aquecimento, reservatório cilíndrico vertical para armazenamento da água de aquecimento (Salvagnini e Gedraite, 2001).

Figura 1 - Planta piloto utilizada

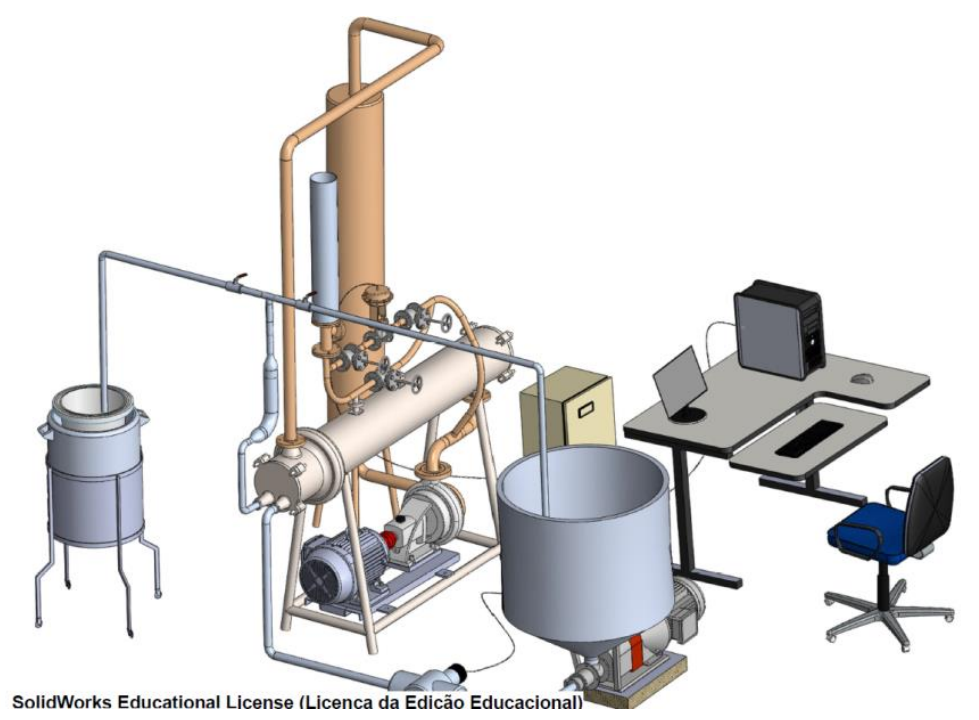

Foram empregados os resultados experimentais obtidos por Melero Jr. (2011) para a análise do funcionamento do sistema de controle de vazão estudado neste trabalho. De maneira análoga, foi utilizado o mesmo modelo da planta desenvolvido por Bicalho, Kunigk e Gedraite (2015) para representar o comportamento da cinética de remoção dos resíduos.

O modelo da planta em estudo foi desenvolvido no ambiente Simulink® do aplicativo Matlab® e contemplou todo o sistema estudado, bem como o cenário de flutuações no valor da vazão de água de enxágue, que tipicamente são verificadas nas instalações industriais. O modelo contemplou todo o sistema estudado e é composto por 06 subsistemas, como apresentado no diagrama de blocos da Figura 2.

No subsistema "1", são apresentados o modelo de referencia e a planta multimodelo, responsáveis por gerar os sinais de $\boldsymbol{p} \boldsymbol{H}^{\text {target }}$ e $\boldsymbol{p} \boldsymbol{H}^{\text {meas }}$ respectivamente. Estes sinais são enviados para o subsistema " 2 ", responsável por calcular o sinal de erro de $\mathrm{pH}\left(\boldsymbol{\varepsilon}_{\boldsymbol{p} \boldsymbol{H}}\right)$. Simultaneamente, o subsistema "3" calcula o erro devido ao volume de água de lavagem gasto no processo $\left(\varepsilon_{V}\right)$. Os sinais gerados pelos subsistemas "2" e "3" são empregados para calcular o valor do set-point remoto a ser usado pelo controlador de vazão. Isto é feito no 
subsistema "4". O subsistema "5" modela matematicamente o comportamento da malha de controle de vazão de água de enxágue e o subsistema " 6 " modela matematicamente o comportamento do totalizador e integrador de vazão.

Figura 2 - Diagrama de blocos do modelo estudado (Fonte: Os Autores)

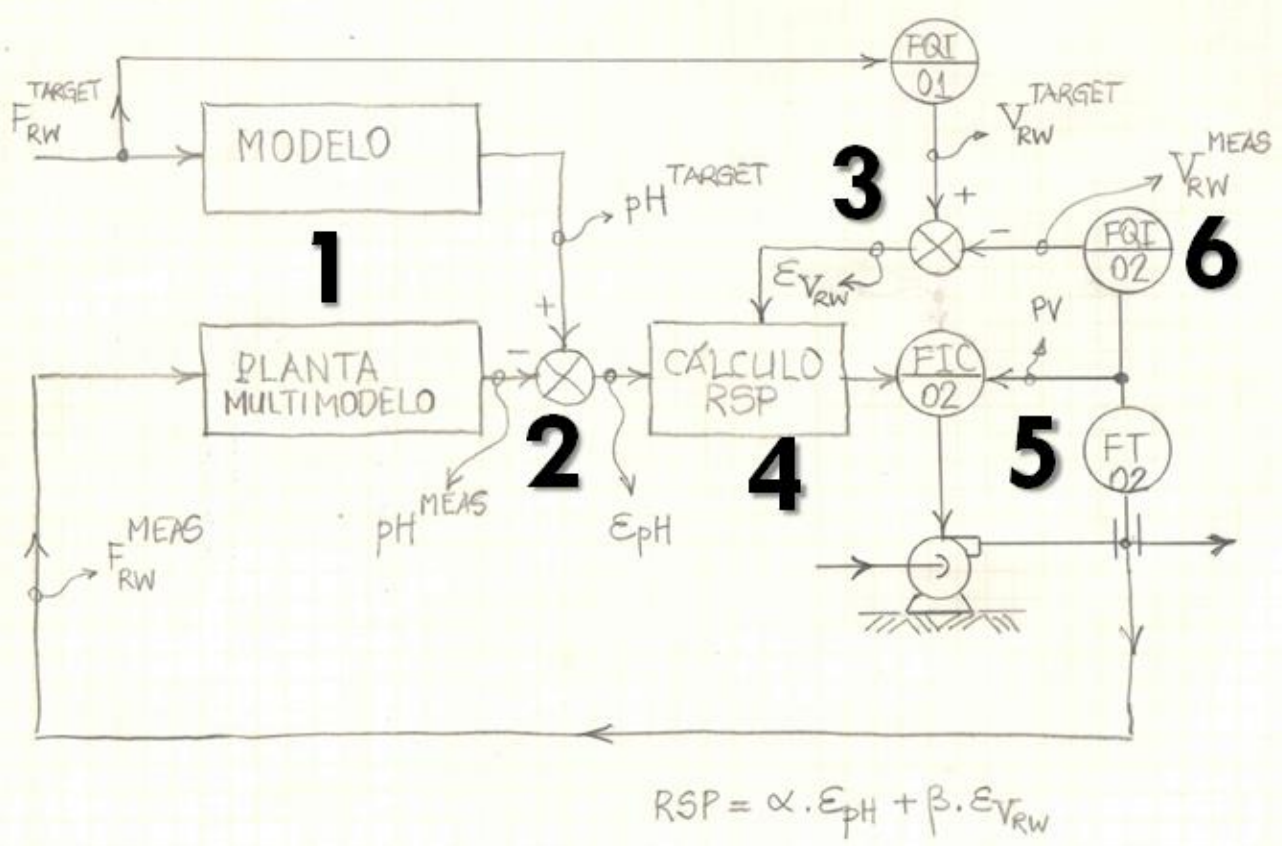

O diagrama de simulação correspondente ao controlador de vazão (subsistema "5"), implementado no aplicativo simulink $₫ /$ matlab®, é apresentado na Figura 3.

Figura 3 - Diagrama de simulação do subsistema "5" 


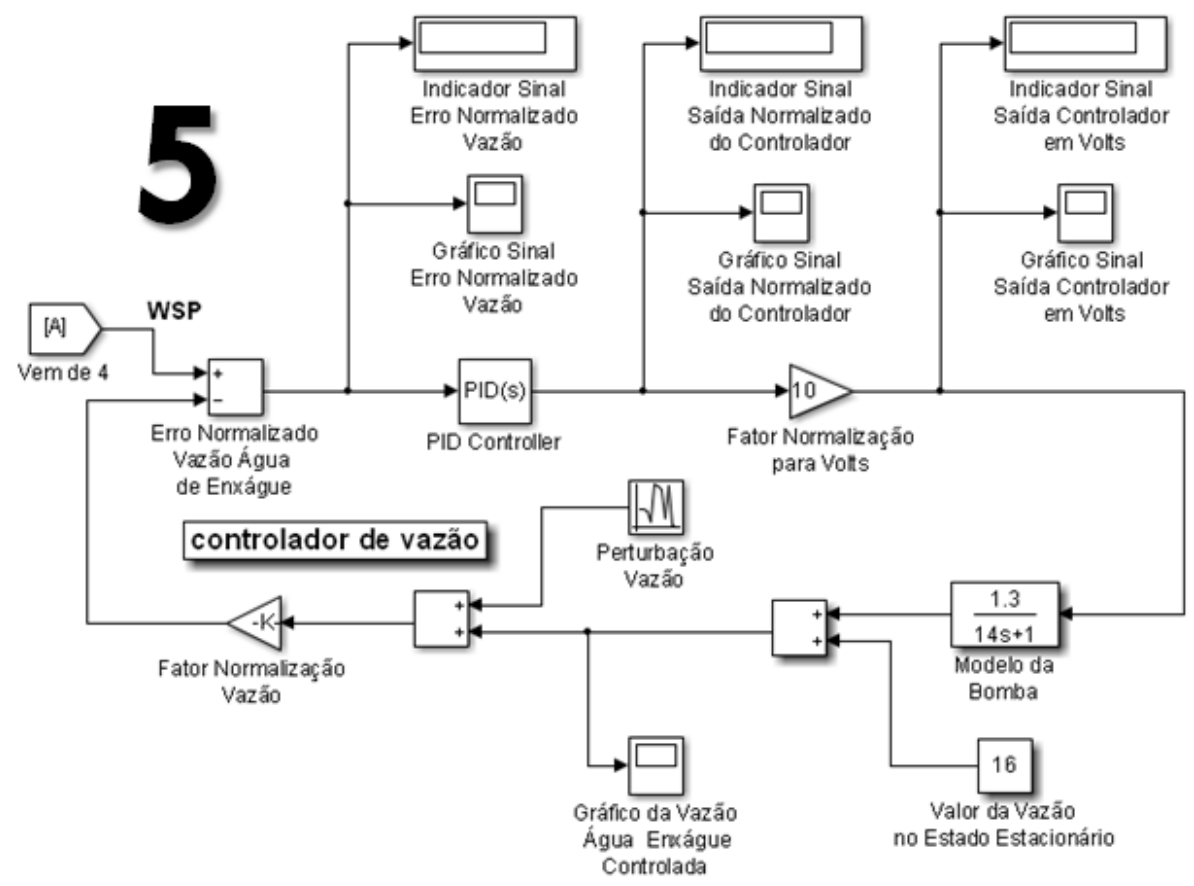

\section{RESULTADOS E DISCUSSÃO}

Com base nos resultados experimentais obtidos por Melero Jr. (2011) para a vazão de $9 \mathrm{~L} / \mathrm{min}$ e nos resultados das simulações realizadas com o emprego do modelo desenvolvido neste trabalho, é apresentado na Figura 4 o comportamento da trajetória desejada para o comportamento do set-point do $\mathrm{pH}\left(\mathrm{pH}^{\text {target }}\right)$ e do $\mathrm{pH}$ medido $\left(\mathrm{pH}^{\text {meas }}\right)$.

Figura 4 - Comportamento temporal do valor do $p H^{\text {target }}$ e do $p H^{\text {meas }}$

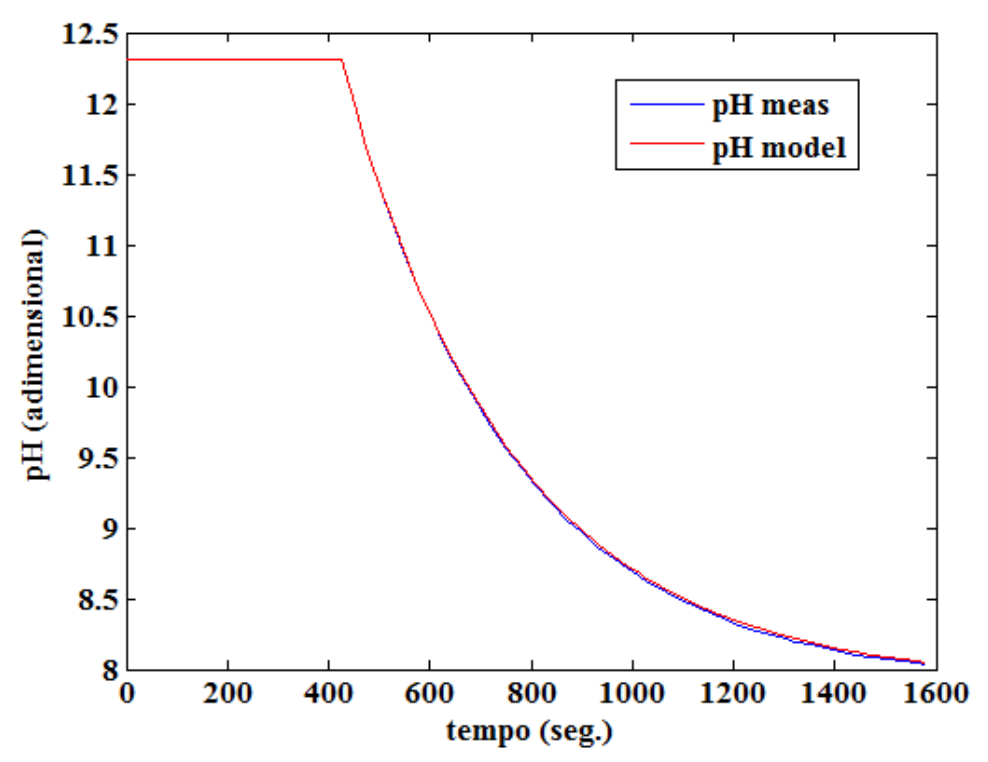

Como pode ser observado a partir do gráfico, o comportamento do valor medido $\left(p H^{\text {meas }}\right)$ e o valor desejado para o $\left(p H^{\text {target }}\right)$ - ambos simulados pelo subsistema " 1 " - é possível verificar que o afastamento entre os valores apresentados é muito pequeno, levando 
à conclusão de que o modelo representa de maneira adequada e coerente o comportamento do sistema em estudo.

O comportamento temporal do valor do set-point remoto normalizado e do valor medido - também normalizado - da vazão de água de enxágue é apresentado na Figura 5. Cumpre salientar que a trajetória deste valor é definida pelos subsistemas " 2 ", "3" e "4" do modelo desenvolvido neste trabalho. O valor temporal do set-point remoto da vazão de água de enxágue é afetado por fatores de ponderação $(X, Y)$ previamente escolhidos com base em análise de sensibilidade realizada. Os valores mais adequados foram $X=0,5$ e $Y=0,5$. Eles representam o peso a ser usado no cálculo do valor do erro do $\mathrm{pH}$ e no erro do Volume, respectivamente.

O modelo apresenta um comportamento bastante agressivo para a variação do valor do set-point de vazão normalizada de água de enxágue. Contudo, o valor controlado apresenta comportamento mais suave para o valor da mesma em razão da sintonia do controlador ter sido realizada com o emprego de valores para os parâmetros ganho e tempo integral mais suaves.

Os valores para os parâmetros ganho e tempo integral do controlador de vazão foram escolhidos com base em análise de sensibilidade realizada com o subsistema "5", resultando nos seguintes valores: ganho $\left(K_{P}=0,01\right)$ e tempo integral $\left(\tau_{I}=0,01 \mathrm{~min}\right.$. $)$.

Figura 5 - Comportamento do valor do set-point remoto da vazão

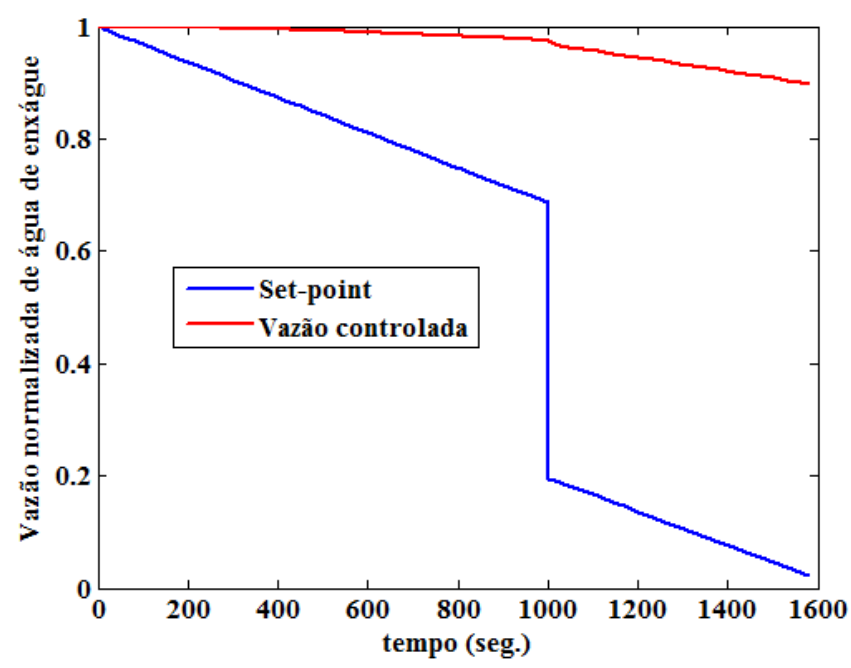

O comportamento da variação do valor simulado da vazão de água de enxágue é apresentado na Figura 6 ressaltando-se o fato de que o valor controlado apresenta comportamento mais suave para o valor da mesma em razão da sintonia do controlador ter sido realizada com o emprego de valores para os parâmetros de sintonia do controlador de vazão como citado anteriormente.

Figura 6 - Comportamento temporal do valor da vazão de água de enxágue 


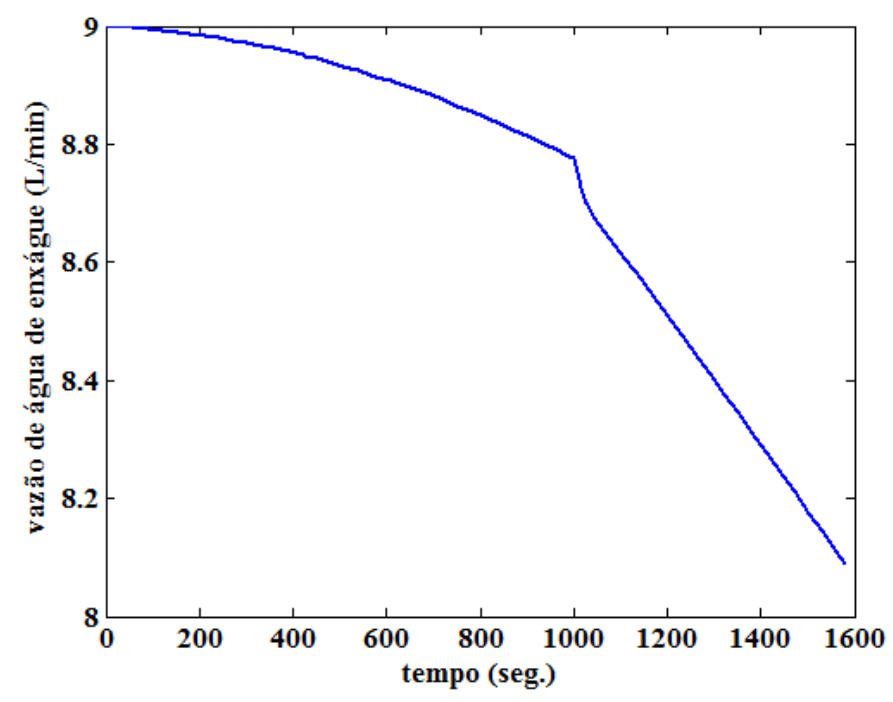

A economia de água obtida com a proposta apresentada neste trabalho foi de aproximadamente $7 \mathrm{~L}$, reduzindo o consumo na etapa de enxágue alcalino de $236,7 \mathrm{~L}$ para 229,7 L.

\section{CONCLUSÃO}

Os modelos desenvolvidos se mostraram bastante simples e adequados, se ajustando bem aos dados experimentais referentes ao comportamento temporal do $\mathrm{pH}$, além do fato de permitir fácil implementação na base de dados de sistemas digitais de controle.

O controlador de vazão foi efetivo na correção do valor desta variável do processo com o tempo, permitindo a redução gradual de seu valor de forma suave.

Com base nos resultados obtidos e nos modelos implementados, pode-se verificar a redução no consumo de água de lavagem da ordem de $3 \%$ e com isso uma economia de energia elétrica correspondente.

\section{REFERÊNCIAS}

BANSAL, B., CHEN, X. D. A Critical Review of Milk Fouling in Heat Exchangers. Comprehensive Reviews in Food Science and Food Safety. Institute of Food Technologists. v.5, p. $27-33,2006$.

BREMER, P.J., FILLERY, S. \& McQUILLAN, A. J. Laboratory scale Clean-In-Place (CIP) studies on the effectiveness of different caustic and acid wash steps on the removal of dairy biofilms. Int. J. Food Microbiol., v.106 , p. 254 - 262, 2006.

BICALHO, B. P.; KUNIGK, L.; GEDRAITE, R. (2015). Influência do emprego de vazões variáveis de água de enxágue sobre a cinética de remoção de resíduos de solução detergente alcalina em trocador de calor feixe tubular. In: Proc. of XI Congresso Brasileiro de Engenharia Química em Iniciação Científica, 19 a 22 de julho de 2015, Campinas - SP. 
GEORGIADIS, M. C., ROTSTEIN, G. E. \& MACCHIETTO, S. Modeling and Simulation of Shell and Tube Heat Exhangers under Milk Fouling. AIChe Journal. v. 44, No. 4, p. 959 - 971, 1998.

MELERO Jr., V. 2011. 'Instrumentação e identificação de um processo de sanitização cinética CIP'. Centro Universitário do Instituto Mauá de Tecnologia, São Caetano do Sul - (Dissertação de Mestrado).

SALVAGNINI, W.; GEDRAITE, R. (2001). Rotina de Experimento para trocador de calor feixe tubular. São Caetano do Sul, SP: CEUN-IMT.

\section{AGRADECIMENTOS}

Os autores agradecem à UFU, ao IMT e à Fapemig (Fundação de Amparo à Pesquisa do Estado de Minas Gerais) pelo apoio em pesquisas no projeto No TEC-APQ-02100-12 (Estudo da Otimização de Sistema de Limpeza CIP). 